\title{
The hippocampal inhibition deficit in positively reinforced discrete trial learning*
}

\author{
THOMAS B. POSEY \\ Murray State University, Murray, Ky. 42071
}

This experiment investigated the effects of bilateral hippocampectomy in a learning task that made positive reinforcement contingent on the acquisition of a slow running response in a straight alley runway. Hippocampectomized $(\mathrm{H})$ rats along with normal $(\mathrm{N})$ and cortical $(\mathrm{C})$ controls were run under one of two conditions: prior training on a continuous reinforcement schedule (Condition $S$ ) or no prior training (Condition NS). It was found that: $\mathrm{H}$ Ss ran reliably faster and received reliably fewer reinforcements than $\mathrm{N}$ and $\mathrm{C}$ Ss. The results were seen as generally supporting the Douglas (1967) model of hippocampal function.

Douglas \& Pribram (1966) have suggested that the hippocampus is a primary center for response inhibition. This model has received wide support and it is well established that bilateral damage to the hippocampus produces a behavioral deficit that becomes apparant in passive avoidance situations, most types of extinction, reversal training, response alternation, and some types of response inhibition (Douglas, 1967). Douglas (1967) has concluded that bilateral hippocampal lesions produced a unitary deficit which is manifested as an inability to inhibit both learned and unlearned prepotent responses.

Many studies cited by Douglas (1967) used operant situations and a number (McCleary, 1961; Isaacson \& Wick elgren, 1962; Kimble, 1963; Snyder \& Isaacson, 1965) have made use of the passive avoidance situation. Although hippocampal ablation effects have been studied in discrete trial and nonpunishment situations, the behavior of hippocampectomized animals in situations where inhibitory behavior leading to positive reinforcement may be successively acquired over discrete trials, has not been directly investigated.

The study undertaken here investigated the behavior of hippocampectomized and control rats under conditions of positive reinforcement for slow speeds in a straight alley runway. The specific schedule, suggested by Logan (1960), was such that an animal received reward only if he entered the goalbox within a particular time interval. The major experimental question was would hippocampally ablated rats acquire an inhibitory response (slow running) across repeated, positively reinforced trials.

*This report is drawn from the author's dissertation done at Texas Tech University. The author is indebted to his chairman, Dennis C. Cogan. into the goalbox, and the third was $27.8 \mathrm{~cm}$ into the goalbox. Reinforcement in the form of wet mash was presented into the end of the goalbox in a small metal cup on the end of an automatic mechanical arm. A standard $15.2 \times 22.8 \times 15.2 \mathrm{~cm}$ metal cage with a plywood top served as the intertrial interval (ITI) confinement box.

\section{PROCEDURE}

Surgery began following 5 days of laboratory acclimatization and proceeded in two sessions. On Days 6 and 7 following the Ss' arrival, surgery was performed on the Ss that served under the $\mathrm{S}$ condition. Surgery was performed on the NS animals on Days 10 and 11 . The time difference allowed equal postoperative recovery for all Ss since the shifted Ss began acquisition 4 days early. Altogether 12 Ss were subjected to bilateral ablation of the posterior-dorsal hippocampus and overlying cortex, and 12 Ss received bilateral ablation of only the cerebral areas similar to those removed by the hippocampectomies. The surgical procedures of Kimble (1963) were followed throughout.

Following surgery all Ss were maintained on ad lib food and water for 10 days. On Day 1 of the experiment the three groups of the $S$ condition were placed on 23 -h food deprivation, receiving wet mash for $1 \mathrm{~h}$ each day. Animals assigned to the NS condition were placed on the same deprivation schedule on Day 5. All Ss received reinforcement pretraining by being allowed to eat in the closed goalbox for $30 \mathrm{sec}$ on the third and fourth days of their deprivation. On the fifth day of their deprivation all Ss were placed in the startbox with the doors open and reinforcement removed, allowed to explore the runway for $10 \mathrm{~min}$, and then removed from the goalbox. Ss were pretrained, run, and fed in a counterbalanced order and at the same time of day throughout the experiment. In all cases an $\mathbf{S}$ was fed after the following $S$ had been returned to its home cage.

Table 1

F Ratios for Analyses of Variance on Median Latencies for Start, Run, and Goal Runway Segments

\begin{tabular}{lrrrr}
\hline \multicolumn{1}{c}{ Source } & df & Start & Run & Goal \\
\hline Between Ss & & & & $8.19^{*}$ \\
A (S and NS Conditions) & 1 & $8.08^{*}$ & n.s. & $23.30^{\dagger}$ \\
B (H, C, and N Groups) & 2 & $12.58 \dagger$ & n.s. & n.s. \\
AB & 2 & n.s. & n.s. & \\
Error & 30 & & & $9.47 \dagger$ \\
Within Ss & & & & $3.09^{*}$ \\
C (Days) & 9 & $5.22 \dagger$ & $6.87 \dagger$ & $2.47^{*}$ \\
AC & 9 & $8.62 \dagger$ & $7.17 \dagger$ & n.s. \\
BC & 18 & $3.54 \dagger$ & n.s. & n.s. \\
ABC & 18 & n.s. & & \\
Error & 270 & &
\end{tabular}

$* p<.01,+p<.001$ 


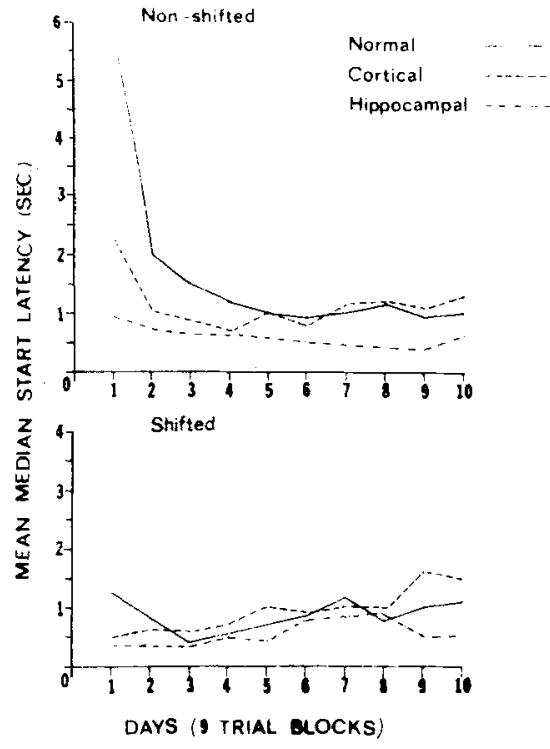

Fig. 1. Mean median start segment latencies for normal, cortical, and hippocampal groups in shifted and nonshifted conditions.

The daily session of nine trials began by removing the $S$ from its home cage and placing it in the ITI box for 20 sec after which the $S$ was placed in the startbox, the doors were opened, and the $\mathrm{S}$ was allowed to traverse the runway. On all trials the $S$ was removed to the ITI box for $20 \mathrm{sec}$ prior to the next trial. Acquisition for $S s$ in Condition $S$ began on the day following their runway exploration day and proceeded at nine trials a day for 4 days. During this period, the Ss were run on a continuous reward schedule receiving a $10-\mathrm{sec}$ period of access to wet mash on every trial beginning when they entered the goalbox.

On the fifth day of acquisition for the groups in Condition $\mathrm{S}$, which was the next day after runway exploration for the groups in Condition NS, all animals in both conditions began acquisition of a differential reinforcement for slow speeds schedule. Handling and running procedures remained the same as those used for the S Ss in preshift training. The differential reinforcement of slow speeds continued at nine trials a day for 10 days. During this period, reinforcement was present in the goalbox for $10 \mathrm{sec}$ only if the $S$ entered the goalbox between 5 and $35 \mathrm{sec}$ after the startbox door was opened. If the $S$ entered the goalbox either before 5 sec had elapsed or after 35 sec had elapsed, he was confined in the goalbox without reward for $10 \mathrm{sec}$.

At the end of the experiment, the four groups of operated animals were sacrificed and perfused. The brains were then extracted, stained, histologically sectioned, and photographed after every 10th 50-micron section.

\section{RESULTS}

The data in the form of daily median latencies for the start, run, and goal runway segments were analyzed by means of three split-plot factorial analyses of variance ( 2 by 3 by 10 ). Each of these examined conditions (S-NS) and groups ( $\mathrm{H}, \mathrm{C}$, and $\mathrm{N}$ ) across the 10 days of speed-contingent training. The results of the analyses are shown in Table 1, and the latencies are presented in Figs. 1, 2, and 3 .

The $S$ Condition resulted in significantly faster running in the start and goal segments. In the start segment $\mathrm{H}$ Ss ran significantly faster than the Ss in each of the other two groups. $\mathrm{C}$ and $\mathrm{N}$ Ss were not significantly different. In the goal segment, $H$ Ss ran significantly more slowly than Ss in each of the other two groups. Again, there was no significant difference between $\mathrm{C}$ and $\mathrm{N}$ Ss. In all segments there was a significant trials effect demonstrating learning.

The number of reinforcements an $S$ received was equal to the number of trials on which it ran the length of the runway in more than $5 \mathrm{sec}$ (but less than the allowed maximum time of $35 \mathrm{sec})$. Therefore, an analysis of total number of reinforcements revealed the degree to which Ss learned to inhibit fast running. The total number of reinforced trials per $\mathbf{S}$ was analyzed for conditions and groups using a 2 by 3 design. Both main effects were significant: conditions (S-NS), $\mathrm{F}=3.94, \mathrm{df}=1,30, \quad \mathrm{p}<.05, \quad$ and groups $(\mathrm{H}-\mathrm{C}-\mathrm{N}), \mathrm{F}=23.19, \mathrm{df}=2,30$, $\mathrm{p}<.001)$. The interaction was not

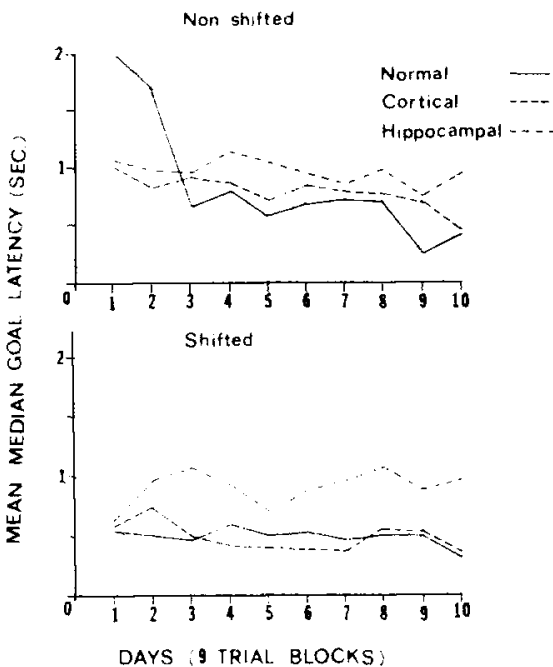

Fig. 3. Mean median goal segment latencies for normal, cortical, and hippocampal groups in shifted and nonshifted conditions.

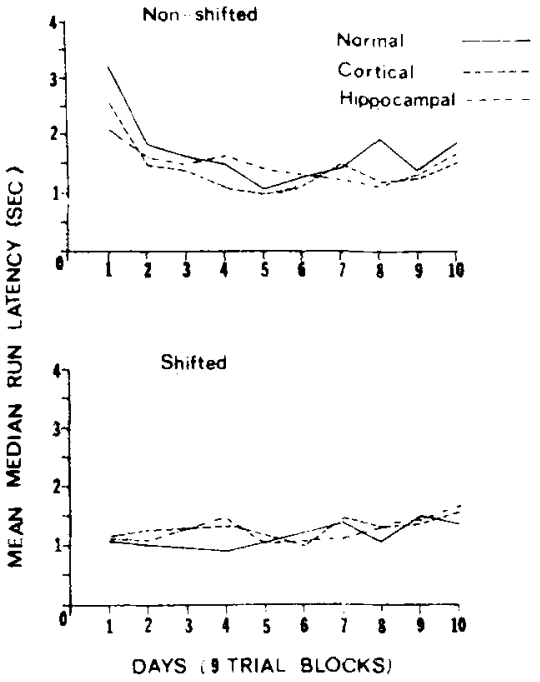

Fig. 2. Mean median run segment latencies for normal, cortical, and hippocampal groups in shifted and nonshifted conditions.

significant. The $\mathrm{S}$ condition resulted in significantly fewer reinforced trials. Appropriate analysis of the groups effect showed $\mathrm{H}$ Ss to have received significantly fewer reinforced trials than Ss in either of the other groups and showed no significant difference between the $\mathrm{C}$ and $\mathrm{N}$ groups. The mean number of reinforcements for each group across conditions were $H$, $7.6 ; \mathrm{C}, 27.0$; and $\mathrm{N}, 29.9$, where the total possible was 90 .

The histological examination of the brains of the $H$ and $C$ Ss led to these conclusions; no $C S$ showed hippocampal damage, no $\mathrm{H} S$ showed thalamic damage, the amount of hippocampus removed in the $\mathrm{H}$ Ss ranged between approximately $60 \%$ and $75 \%$, and slightly smaller amounts of cortex were removed in C Ss than in H Ss.

In this discrete-trial situation in which positive reinforcement was contingent on slow running, hippocampectomized rats, unlike control Ss, were unable to inhibit a fast running response. Further, the lack of ability to learn to run slowly for reinforcement was equally apparent in hippocampal Ss who had been previously trained on continuous reinforcement as well as in those who had received no such prior training. Although both shifted and nonshifted hippocampals ran significantly more slowly than the other groups in the goal segment of the runway, they were appararently unable to inhibit the tendency to run fast to a degree that would permit them to receive reinforcement. Indeed, in the start segment of the runway where most of the normal and cortical Ss exhibited 
long latencies, the hippocampal Ss continued to demonstrate very short latencies. The fact that the hippocampal Ss ran more slowly in the goal segment might suggest the operation of a frustrative nonreward effect (Amsel, 1958, 1962) to which the hippocampals continued to respond after the other $S s$ had acquired other more effective behaviors.

The study supports the Douglas (1967) model and demonstrates its ability to handle a positive reinforcement, discrete-trial inhibitory situation.
AMSEL, A. The role of frustrative non-reward in noncontinuous reward situations. Psychological Bulletin, 1958, $55,102-119$

AMSEL, A. Frustrative non-reward in partial reinforcement and discrimination learning: Some recent history and a theoretical extension. Psychological Review, 1962, 69, 306-328.

DOUGLAS, R. J. The hippocampus and behavior. Psychological Bulletin, 1967, 67, 416-442.

DOUGLAS, R. J., \& PRIBRAM, K. H. Learning and limbic lesions. Neuropsychologia, 1966, 4, 197-220.

ISAACSON, R. L., \& WICKELGREN, W. o. Hippocampal ablation and passive avoidance. Science, 1962, 138, 1104-1106.
KIMBLE, D, $P$ The effects of bilateral hippocampal lesions in rats. Journal of Comparative and Physiological Psychology, 1963, 56, 273-283.

LOGAN, F. A. Incentive. New Haven: Yale University Press, 1960.

MCCLEARY, $R$. A. Response specificity in the behavioral effects of limbic lesions in the cat. Journal of Comparative \& Physiological Psychology, 1961, 54, 605-613.

SNYDER, D. R., \& ISAACSON, R. L. The effects of large and small bilateral hippocampal lesions on two types of passive avoidance responses. Psychological Reports, 1965, 16, 1277-1290. 